\title{
Using confocal laser scanning microscopy, scanning electron microscopy and phase contrast light microscopy to examine marine biofilms
}

\author{
T. A. Norton ${ }^{1}$, R. C. Thompson ${ }^{1, * * *}$, J. Pope ${ }^{2}$, C. J. Veltkamp ${ }^{3}$, B. Banks ${ }^{4}$, C. V. Howard ${ }^{2}$, S. J. Hawkins ${ }^{1, * *}$ \\ 1Port Erin Marine Laboratory, School of Biological Sciences, University of Liverpool, Port Erin, Isle of Man IM9 6JA, United Kingdom \\ ${ }^{2}$ Department of Foetal and Infant Pathology, and ${ }^{3}$ School of Biological Sciences, University of Liverpool L69 3BX, United Kingdom \\ ${ }^{4}$ School of Biological Sciences, University of Southampton, Southampton SO16 3BX, United Kingdom
}

\begin{abstract}
Confocal laser scanning microscopy (CLSM) was used to examine living organisms within marine biofilms growing on microscope slides and on natural opaque and uneven substrata such as rocks and shells. The results were compared to images of identical fields observed under transmitted light and phase contrast microscopy and scanning electron microscopy. Confocal microscopy proved superior in severdl respects: (1) It gave clear images of organisms even if they were overlaid with a thick layer of mucus, other organisms and debris. (2) It did not require the biofilm to be disrupted or dried and allowed samples to be re-examined at intervals. (3) It could also distinguish living (fluorescing) organisms from dead cells or inorganic matter. (4) Examining optical 'slices' of samples allowed the 3 dimensional structure of the biofilm to be visualised. However, species identification, particularly of diatoms, was much easier using scanning electron microscopy. Methods were developed for overlaying a fixed grid on samples so that specific sites or individual organisms could be accurately relocated for re-examination. Appropriate staining methods were also evaluated. Confocal microscopy will prove to be an invaluable aid for examining the structure and growth of living biofilms in studies of shore ecology and marine fouling.
\end{abstract}

KEY WORDS: Confocal microscopy $\cdot$ SEM - Self-registration · Biofilms · Microalgae $\cdot$ Cyanobacteria $\cdot$ Biofouling

Biofilms cover most hard objects in aquatic habitats. They consist largely of water ( 70 to $95 \%$ of the fresh weight) held by highly hydrated extracellular polymers (Wahl 1989, Flemming 1993). Embedded in this mucus matrix are bacteria, cyanobacteria, diatoms, flagellates and protozoans, the proportions of each

\footnotetext{
-Addressee for correspondence. E-mail: rct@soton.ac.uk

- Present address: Division of Biodiversity \& Ecology. School of Biological Sciences, Bassett Crescent East, University of Southampton, Southampton SO16 7PX, United Kingdom
}

varying seasonally and in different habitats (Underwood 1984, Hill \& Hawkins 1991, Anderson 1995). The organisms may be very abundant; estimates of $3 \times$ $10^{7}$ bacteria (Hendy 1951) and $2.7 \times 10^{5}$ diatoms $\mathrm{cm}^{-2}$ (Edyvean \& Moss 1986) have been made for marine biofilms.

These films may be up to $2 \mathrm{~mm}$ thick (Callow \& Edyvean 1990) although in turbulent water they rarely exceed $1 \mathrm{~mm}$ and are usually much thinner (Wimpenny \& Peters 1987). In the sea biofilms dominate the rock/water interface, contributing to primary productivity and nutrient cycling (Workman 1983, Bustamante et al. 1995). They also influence the settlement of the larvae of sessile invertebrates (Holmstroem et al. 1992, Tritar et al. 1992, Wieczorek et al. 1996) and the ability of rock dwellers such as seaweeds and barnacles to adhere (Norton 1983, Neal \& Yule 1994). Biofilms are readily consumed, rendering both the resident cells and absorbed dissolved organic matter available to protozoan and larger browsers (Hill \& Hawkins 1991, Bernhard \& Bowser 1992, Decho \& Lopez 1993). Films encourage corrosion in both metals and concrete (Callow \& Edyvean 1990) and can greatly increase skin friction, reducing the speed of ships by up to $15 \%$ (Lewthwaite et al. 1985). They also encourage fouling by larger organisms (Wahl 1989).

Surprisingly little is known about the distribution of organisms within the film (Hall 1992). This is largely because of technical difficulties in viewing intact living biofilms. Conventional transmitted light microscopy can only be used if the underlying substratum is transparent. Hence microscope slides can be used to study inital colonisation and film formation (MacLulich 1986), but as the film becomes thicker slime blurs the image. Alternatively living biofilms can be viewed on 
opaque surfaces using fluorescence microscopy (Jones 1974, Becker et al. 1997), but the images may be confused by fluorescing organisms which are beyond the focal plane of interest (Shotton 1989). Scanning electron microscopy (SEM) is the most commonly used method for examining marine biofilms because it offers exceptionally good depth of focus and can be used to produce clear images of organisms on opaque substrata across a wide range of magnifications (e.g. MacLulich 1986, Hill \& Hawkins 1990, Blenkinsop \& Loch 1994, Thompson et al. 1996). This technique can only be used to examine the film's surface, however, since underlying layers become obscured. In additition, preparation for SEM kills the constituent organisms and shrivels the film, destroying its structure and possibly exaggerating the relative abundance of diatoms whose silica frustules are unaffected by drying (MacLulich 1986, Thompson et al. 1996).

Confocal laser scanning microscopy (CLSM) has been developed during the last decade. This technique offers a capability for direct non-invasive optical sectioning of living material and provides images which are free from out of focus blur (see Shotton 1989 for review). CLSM has successfully been used to examine different layers within cultured bacterial biofilms (Lawrence et al. 1991, Caldwell et al. 1992) and more recently to visualise hydrated marine biofilms (Nagarkar \& Williams 1997). Our paper assesses the utility of confocal microscopy for viewing living mixed species marine biofilms and compares the results obtained with those from light microscopy and SEM.

Materials and methods. Materials: Marine biofilms were cultured on glass microscope slides placed on perspex slide racks in either a marine aquarium or the brackish waters (mean salinity $28.7 \%$ ) of Princes Dock, Liverpool, UK, at a depth of $0.3 \mathrm{~m}$. Slides were removed randomly at intervals, rinsed in seawater and stored in glutaraldehyde (5\% in filtered seawater). Natural substrata (rock chips, mussel and limpet shells) were collected from the intertidal zone at Port St. Mary, Isle of Man, UK.

Staining: As CLSM only images fluorescing bodies, stains were used to induce fluorescence in other parts of the cell in a colour contrasting with the natural red fluorescence of the chloroplasts. After testing several stains, we found that the best results were obtained from films stained for $1 \mathrm{~h}$ in sodium fluorescein (a $0.3 \%$ solution made up in filtered seawater) which fluoresces green, and in acridine orange. Other stains that proved useful were fluorescein isothiocyanate (FITC) which binds to amino groups of protein and gives a strong green fluorescence that does not mask the autofluorescence of the chloroplasts (Sherr \& Sherr 1983). FITC-labelled concanavalin-A was used to stain limpet mucus as the lectin concanavalin-A binds to mucoPolysaccharides (specifi- cally to -glucopyranosyl residues and -manopyranosyl residues).

Confocal laser scanning microscopy: Specimens were viewed using a Biorad 600 CLSM. A $\times 100.5$ NA lens was used with air as the visualising medium, or $a \times 601.4 \mathrm{NA}$ lens with water as a visualising medium. Simultaneous phase contrast examinations were also made, using the second channel of the CLSM. Slides immersed in the dock for $45 \mathrm{~d}$ were used to compare CLSM, phase contrast and SEM images, as by this time several welldeveloped layers of organisms were present.

Self-registration: In order to examine the same specimens under SEM, and for repeated viewing under the confocal microscope, a method of self-registration was required so that specific areas could be relocated. Transmission electron microscopy grids were used as these were visible under both SEM and CLSM. Prior to staining, $300 \mu \mathrm{m}$ mesh size copper grids were glued to the surface of the slides or natural substrata with epoxy resin and allowed to dry. The grids, being small (3.05 $\mathrm{mm}$ in diameter), lay close to the specimen surface and when anchored with epoxy resin adhered securely even after SEM preparation.

Precisely registered areas were obtained by means of co-ordinates on plans of the grid and by using distinctive features on the confocal pictures themselves. The use of a superimposed grid allowed identical locations on a sample to be readily refound for repeated examination, even after the specimen had been removed from the microscope and prepared for SEM as detailed below. Multiple images per grid and per specimen were photographed or stored digitally.

Scanning electron microscopy: Specimens were prepared using a method of freeze dehydration (Veltkamp et al. 1994) and viewed in a Philips XL 30 SEM at accelerating voltages of 10 to $15 \mathrm{kV}$

Results. By focusing at different depths within a biofilm, CLSM provided optical slices from within the film without disturbing the overlying mucus. For images taken at depth intervals of $10 \mu \mathrm{m}$, each image was distinctly different from the others and was not obscured by the layers of cells above (Fig. 1a-c). At comparable depths within the film, phase contrast produced a very poor image and the desiccation required for SEM collapsed the structure of the film.

The registration grid enabled us to compare the images obtained with CLSM with views of identical fields taken with phase contrast and SEM. Over 30 sets of such triple images were captured. The pictures obtained by the 3 methods varied considerably (e.g. Fig. $2 a-c\}$. Although some organisms are visible in all 3 images, others seen under both phase contrast and SEM (arrowed) were invisible under CLSM. As CLSM only registers fluorescence, non-living debris and empty diatom frustules (which do not fluoresce) were 

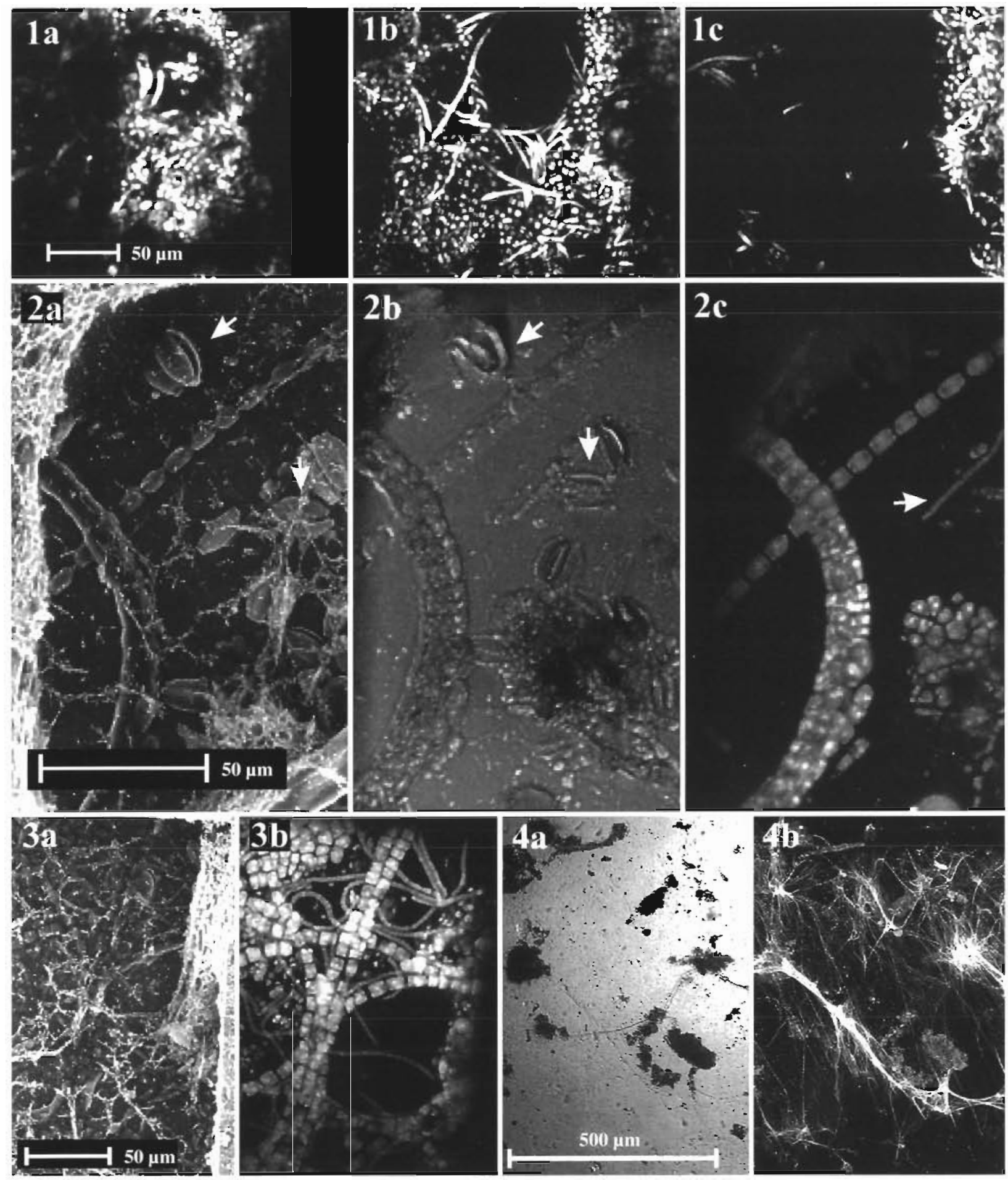

Figs. 1 to 4 . Fig. 1. Three images of a natural biofilm viewed at different depths within the same field of view on a rock sample taken from the intertidal zone at Port St. Mary, Isle of Man, UK. The optical slices were taken (a) just sub-surface, (b) $13 \mu \mathrm{m}$ and (c) $23 \mu \mathrm{m}$ below the film's surface. Fig. 2. Biofilm on a glass microscope slide after $45 \mathrm{~d}$ immersion in the Princes Dock, Liverpool, UK. The same field was visualised by (a) SEM, (b) phase contrast microscopy and (c) CLSM. The arrows in (a) and (b) indicate empty diatom frustules visible under phase contrast and SEM, but 'ignored' by CLSM. The arrow in (c) indicates a cyanobacterial strand clearly visible only under CLSM. Fig. 3. Biofilm on a glass microscope slide after $45 \mathrm{~d}$ immersion in the Princes Dock. The same field was visualised by (a) SEM and (b) CLSM. Depth into film is $18 \mu \mathrm{m}$. Note part of the registration grid on the top and right hand margins of both photographs. Fig. 4. Limpet mucus on a glass microscope slide viewed under (a) transmitted light microscopy and (b) CLSM after staining with FITC-labelled concanavalin-A 


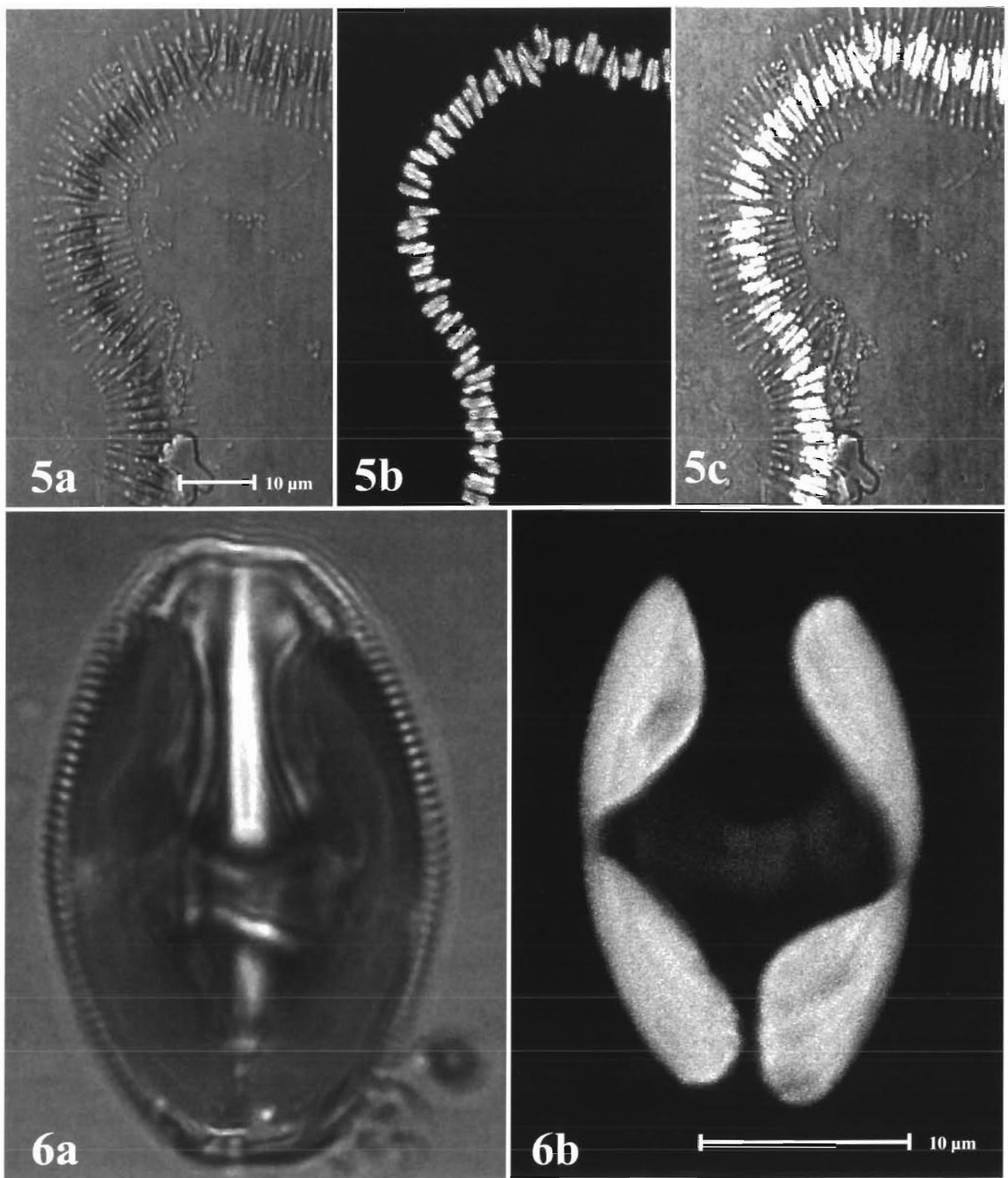

Figs. $5 \& 6$. Fig. 5. Chain of diatoms Fragilarja sp. on a glass microscope slide after 5 d immersion in a marine aquarium and visualised under (a) transmitted light and (b) CLSM, and (c) a composite of the 2 images. Fig. 6. A diatom Amphora sp. on a glass microscope slide after $13 \mathrm{~d}$ immersion in a marine aquarium and visualised under (a) transmitted light and (b) CLSM. Note the distinctive shape and position of the 2 plastids in (b) 
effectively 'erased', but a cyanobacterial strand previously obscured was now apparent.

Comparisons of the same fields under SEM and CLSM clearly demonstrate the ability of the latter to 'clean up' the image (Fig. 3a, b). The image under SEM is festooned by strands and patches of dried mucus which obscure the underlying organisms, whereas under CLSM the hydrated mucus is invisible. In each picture a corner of the registration grid is visible. FITClabelled concanavalin enabled visualisation of the 3 dimensional structure of the mucus trail left by a limpet when crawling across a 4 wk old biofilm cultured on a glass microscope slide (Fig. $4 \mathrm{a}, \mathrm{b}$ ).

Confocal microscopy produced images adequate to allow the identification of some micro-organisms to at least generic level (Figs. $5 \& 6$ ). The best images for the purpose of identification were often obtained using computer software to combine images from confocal and light microscopy (Fig. 5c), but for counting cells, CLSM was far superior (Fig. 5b). The distinctive shape of the plastids of some diatoms was much clearer under CLSM than transmitted light (Fig. 6a, b).

Discussion and conclusions. Marine biofilms were considered a good test of the confocal laser scanning microscope as they contain layers of a variety of organisms including solitary and colonial diatoms, cyanobacterial filaments, and debris. Where the film was very thin and there was no superficial mucilage cover, it was possible to identify some of the organisms with SEM. As SEM views the surfaces of objects, the silicon frustules of diatoms lying on top of the film were clearly visualised, but beneath mucilage little could be distinguished. Under CLSM, however, the entire depth of biofilms $90 \mu \mathrm{m}$ thick could be readily visualised as there was no masking of the organisms. Even thicker films containing additional layers of cells should not provide an obstacle, as CLSM can resolve images over $100 \mu \mathrm{m}$ within solid bone (Howard et al. 1985). One problem in the present study was that on rugose surfaces it was not possible to determine whether dark patches in the CLSM images represented holes in the film itself or areas in which features of surface relief protruded into the film. This difficulty could be resolved using fluorescence exclusion microscopy to stain gaps between cells rather than to stain the cells themselves (see Caldwell et al. 1992)

CLSM registers only fluorescing bodies such as chloroplasts, but the use of contrasting stains increased the range of fluorescing structures within the cells without masking the autofluorescence of the plastids. In addition, FITC-labelled concanavalin-A was used successfully to stain and hence visualise limpet trails under CLSM. This technique may enable us to assess the extent of limpet trails and to estimate their contribution to biofilms on the shore.
An advantage of CLSM is that it provides bright, distinct images of chloroplasts, making algal cells much easier to count than under other types of microscopy. It also means that dead cells and empty diatom frustules do not register at all so that only living cells are counted. The pigments of some microbial groups differ, for example chlorophyll $a$ and $c$ in diatoms and phycoerythrin in cyanobacteria and cryptophytes. Consequently, the use of filters may allow the distinctive fluorescence of these groups to be readily distinguished for rapid survey purposes.

Some organisms were, however, difficult to identify under CLSM. In marine biofilms diatoms and cyanobacteria predominate (Hill \& Hawkins 1991, Nagarkar \& Williams 1997). The cyanobacteria, which are a notoriously 'difficult' group, disperse their pigments throughout the cytoplasm so that the shape of the cells was clearly visible under CLSM. Hence the chances of identification depend on the relative distinctiveness of cell shape in different species. For diatoms, features of their outer silica frustule are the most widely used taxonomic character for their identification, and the frustule did not fluoresce with any of the stains we used. This made some diatoms difficult to identify although the ability of the confocal microscope to switch to phase contrast sometimes overcame this problem. However, discrete plastids give a distinctive fluorescent signal, and many genera and some species of diatoms have plastids that are characteristic in their shape, number and position within the cell (Cox 1980, 1996) and should therefore be identifiable under CLSM. In general, where more traditional techniques such as SEM can visualise the cells they are more useful than CLSM for the identification of species and, as Nagarkar \& Williams (1997) state, for recording species richness.

By retrieving glass slides from seawater at intervals, we acquired films at different stages in their development. After $11 \mathrm{~d}$ the mucus film was $71.2 \pm 16.2 \mu \mathrm{m}$ (mean $\pm \mathrm{SD}, \mathrm{n}=5$ ) thick and contained several layers of organisms. Focusing on the top then the base of the film using CLSM proved to be a simple and precise method of measuring the increasing thickness of the film.

CLSM is an excellent method for visualising living marine biofilms on natural substrata, even those with uneven microtopography. The principal benefit of the technique is the ability to view living material through thick hydrated mucilage without disturbing overlying layers, and to examine the organisms inhabiting different layers within the film. Laser-mediated optical sections of intact live preparations were made, and with appropriate software they could be reconstructed into a computer digitised image that could be viewed from any orientation (e.g. Wilson 1990, Lichtman 1994). This combination of techniques would enable 
the 3 dimensional architecture of marine biofilms and the interrelations between the constituent organisms to be studied. It should also be possible to monitor the growth and development of individual organisms and whole communities within the film over time.

Acknowledgements. We thank Chris Bridge at the Port Erin Marine Laboratory for his help in preparing the photographic plates. The late Steve Jane of the Biosciences Imaging Group at the University of Southampton rendered useful advice on techniques. Eileen Cox of the Natural History Museum, London, kindly provided taxonomic expertise on the diatoms. The Mersey Docks and Harbour Board permitted us to make use of Princes Dock in Liverpool. J.P. was funded by an N.E.R.C. Research Grant (GR9/1319) and R.C.T. by an N.E.R.C. Studentship (GT4/92/201 A).

\section{LITERATURE CITED}

Anderson MJ (1995) Variations in biofilms colonising artificial surfaces: seasonal effects and effects of grazers. J Mar Biol Assoc UK 75:705-714

Becker $G$, Holfeld $H$, Hasselrot AT, Fiebig DM, Menzler DA (1997) Use of a microscope photometer to analyse in vivo fluorescence intensity of epilithic microalgae grown on artificial substrata. Appl Environ Microbiol 63:1318-1325

Bernhard JM, Bowser SS (1992) Bacterial biofilms as a trophic resource for certain benthic foraminifera. Mar Ecol Prog Ser 83:263-272

Blenkinsop SA, Loch MA (1994) The impact of storm flow on river film architecture. J Phycol 30:807-818

Bustamante RH, Branch GM, Eekhout S, Robertson B, Zoutendyke P. Schleyer M, Hanekom N, Keats D, Jurd M, McQuaid C (1995) Gradients of intertidal primary productivity around the coast of South Africa and their relationship with consumer biomass. Oecologia 102:189-201

Caldwell DE, Korber DR, Lawrence JR (1992) Imaging of bacterial cells by fluorescence exclusion using scanning confocal laser microscopy. J Microbiol Methods 15:249-261

Callow ME, Edyvean RGJ (1990) Algal fouling and corrosion. In: Akatsuka I (ed) Introduction to applied phycology. SPB Academic Publishing, The Hague, p 367-387

Cox EJ (1980) The use of chloroplasts and other features of the living cell in the taxonomy of naviculoid diatoms. In: Ross R (ed) Proc 6th symposium on recent \& fossil diatoms. Koeltz, Koenigstein, p 115-133

Cox EJ (1996) Identification of freshwater diatoms from live material. Chapman \& Hall, London

Decho AW, Lopez GR (1993) Exopolymer environments of microbial flora: multiple and interactive effects on trophic relationships. Limnol Oceanogr 38:1633-1645

Edyvean RGJ, Moss BL (1986) Microalgal communities on protected steel substrata in seawater. Estuar Coast Shelf Sci 22:509-527

Flemming HC (1993) Biofilms and environmental protection. Water Sci Technol 27:1-10

Hall SJ (1992) Review of plant-animal interactions in the marine benthos. Trends Ecol Evol 7:319

Hendy NI (1951) Littoral diatoms of Chichester harbour with special reference to fouling. J R Microsc Soc 71:1-86

Hill AS, Hawkins SJ (1990) An investigation of methods for sampling microbial films on rocky shores. J Mar Biol Assoc UK 70:77-88

Hill AS, Hawkins SJ (1991) Seasonal and spatial variation of epilithic microalgal distribution and abundance and its in- gestion by Patella vulgata on a moderately exposed rocky shore. J Mar Biol Assoc UK 71:403-423

Holmstroem C, Rittschof D, Kelleberg S (1992) Inhibition of settlement by larvae of Balanus amphitrite and Ciona intestinalis by a surface-colonizing bacterium. Appl Environ Microbiol 58:2111-2115

Howard CV, Reed S, Badderly A, Boyde A (1985) Unbiased estimates of particle density in tandem scanning reflected confocal microscopy. J Microscopy 138:203-212

Jones JG (1974) A method for observation and enumeration of epilithic algae directly on the surface of stones. Oecologia $16: 1-8$

Lawrence JR, Korber DR, Hoyle BD, Costerton JW, Caldwell DE (1991) Optical sectioning of microbial biofilms. J Bacteriol 173:6558-6567

Lewthwaite JC, Molland AF, Thomas KW (1985) An investigation into the variation of ship skin frictional resistance with fouling. Trans Roy Inst Naval Architects 127:269-284

Lichtman JW (1994) Confocal microscopy. Sci Am 271 (2): $40-45$

MacLulich JH (1986) Experimental evaluation of methods for sampling and assaying intertidal epilithic microalgae. Mar Ecol Prog Ser 34:275-280

Nagarkar S, Williams GA (1997) Comparative techniques to quantity cyanobacteria dominated epilithic films on tropical rocky shores. Mar Ecol Prog Ser 154:281-291

Neal AL, Yule AB (1994) The tenacity of Elminius modestus and Balanus perforatus cyprids to bacterial films grown under different shear regimes. J Mar Biol Assoc UK 74: 251-257

Norton TA (1983) The resistance to dislodgement of Sargassum muticum germlings under defined hydrodynamic conditions. J Mar Biol Assoc UK 63:181-193

Sherr B, Sherr E (1983) Enumeration of heterotrophic microprotozoa by epifluorescence microscopy. Estuar Coast Shelf Sci $16: 1-7$

Shotton DM (1989) Confocal scanning optical microscopy and its applications for biological specimens. J Cell Sci 94 $175-206$

Thompson RC, Wilson BJ, Tobin ML, Hawkins SJ (1996) Biologically generated habitat provision and diversity of rocky shore organisms at a hierarchy of spatial scales. J Exp Mar Biol Ecol 202:73-84

Tritar S, Prieur D, Weiner R (1992) Effect of bacterial films on the settlement of oysters, Crassostrea gigas (Thunberg 1793). Ostrea edulis (Linnaeus 1750) and the scallop, Pecten maximus (Linnaeus 1758). J Shellfish Res 11 : $325-330$

Underwood A.J (1984) Vertical distribution and seasonal abundance of intertidal microalgae on a rocky shore in New South Wales. J Exp Mar Biol Ecol 78:199-220

Veltkamp CJ, Chubb JC, Birch SP, Eaton JW (1994) A simple freeze dehydration method for studying epiphytic and epizoic communities using the scanning electron microscope. Hydrobiologia 288:3.3-38

Wahl M (1989) Marine epibiosis. I. Fouling and antifouling some basic aspects. Mar Ecol Prog Ser 58:1-2

Wieczorek SK, Murray AWA, Todd CD (1996) Seasonal variation in the effects of hard substratum biofilming on settlement of marine larvae. Biofouling 10:309-330

Wilson T (1990) Confocal microscopy. Academic Press, London Wimpenny JWT, Peters A (1987) Ecology on the microscale. In: Sleigh MA (ed) Microbes in the sea. John Wiley \& Sons, Chichester, p 59=82

Workman C (1983) Comparisons ot energy partitioning in contrasting age-structured populations of the limpet Patella vulgata. J Exp Mar Biol Ecol 68:81-103 